\title{
Contrast Enhanced Ultrasound of Splenic Lymphoma Involvement Case presentation
}

\author{
MELANIA ARDELEAN ${ }^{1}$, ROXANA BUZAS ${ }^{1 *}$, NORINA BASA ${ }^{1}$, DANIEL LIGHEZAN ${ }^{1}$, CORINA DUDA SEIMAN², \\ DANIEL DUDA SEIMAN ${ }^{3}$, NICOLAE CONSTANTIN BALICA ${ }^{4}$, OVIDIU ARDELEAN ${ }^{5}$ \\ "Victor Babes University of Medicine and Pharmacy, Internal Medicine Department, 2 Eftimie Murgu Sq., 300041, Timisoara, \\ Romania \\ 2West University, Chemistry, Biology and Geography Faculty, 4 Vasile Parvan Str., 300223, Timisoara, Romania \\ ${ }^{3}$ Victor Babes University of Medicine and Pharmacy, Department of Cardiology - Ambulatory Internal Medicine, Preventive \\ Cardiology and Cardiovascular Rehabilitation, 2 Eftimie Murgu Sq., 300041, Timisoara, Romania \\ ${ }^{4}$ Victor Babes University of Medicine and Pharmacy, ENT Department, 2 Eftimie Murgu Sq., 300041, Timisoara, Romania \\ ${ }^{5}$ Victor Babes University of Medicine and Pharmacy, Surgery Department I, 2 Eftimie Murgu Sq., 300041, Timisoara, Romania
}

\begin{abstract}
The study present a case of splenic lymphoma in a middle-aged male, showing up with abdominal pain, weight loss and recurrent oral candidosis. Blood test revealed remarkable leukocytosis, anemia and thrombocytopenia. Abdominal ultrasound showed marked splenomegaly with multiple hyperechogenic lesions. Contrast enhanced ultrasound (CEUS), performed on the lower pole of the spleen, showed a lesion lightly hypoenhanced in the arterial time, with progressive washout and marked hypoenhancement in the late phase, raising the suspicion of a malignant pathology. MRI results were consistent with a high suspicion of splenic malignancy, a possible lymphoid infiltration. The peripheral blood smear revealed lymphocytosis with villous lymphocytes, a variant form of hairy cell leukaemia. Iliac crest bone marrow biopsy confirmed the diagnosis. Our aim behind highlighting the topic is to underline the role of CEUS in identifying a malignant lesion, promptly leading us to further hematological investigation.
\end{abstract}

Keywords: splenic lymphoma, hyperechogenic lesions, contrast enhanced ultrasound

The spleen is a unique abdominal organ, with important immunological function, which is able to defend against tumor cells and pathogenic microorganisms, so focal lesions of the spleen represent relatively rare occurrences compared with the frequently studied liver [1-22]. Vascular tumors are the mostcommon primarytumors of the spleen, and most of them are benign [10]. Lymphoma is the most common malignancy of the spleen, although it rarely occurs primary [16]. Metastases are relatively uncommon with a low incidence (1.1\%) [14]. Basic abdominal ultrasound is limited in characterizing focal spleen lesions due to a low contrast between the spleen's parenchyma and the detected lesion. The development of contrast ultrasound agents has given the opportunity to improve diagnosis accuracy for focal spleen lesions [15,21]. Uncommonly reported in the medical literature, primary splenic lymphoma is being increasingly recognized in clinical practice due to imagistic techniques.

\section{Case Rreport}

A 60 years old male patient was showed up to the Internal Medicine Department with abdominal pain in the mezogastric area, left hipocondrum, weight loss (approximately $5 \mathrm{~kg}$ in the past month), and recurrentoral candidosis. Blood tests were performed. A remarkable leukocytosis was detected $-114.86 \times 10^{3} / \mu \mathrm{L}$ (normal range $\left.4-10 \times 10^{3} / \mu \mathrm{L}\right)$, mycrocitary, hypochrome anemia (erythrocytopenia - $3.37 \times 10^{3} / \mu \mathrm{L}$ - normal range $4.5-5.5 \times$ $10^{3} / \mu \mathrm{L}$, haemoglobin (HGB) - $8.8 \mathrm{~g} / \mathrm{dL}$ - normal range 13 $17 \mathrm{~g} / \mathrm{dL}$, haematocrit (HCT) - 28.3\% -normal range 40 $50 \%$, mean corpuscular hemoglobin $(\mathrm{MCH})-26.1 \mathrm{pg}$ normal range 27 - $32 \mathrm{pg}$, mean corpuscular hemoglobin concentration (MCHC) - $31.1 \mathrm{~g} / \mathrm{dL}$ - normal range 31.5 $34.5 \mathrm{~g} / \mathrm{dL}$, thrombocytopenia - $91 \times 10^{3} / \mu \mathrm{L}$ - normal range $150-410 \times 10^{3} / \mu \mathrm{L}$. Next, a basic abdominal ultrasound was performed, revealing: marked splenomegaly $(22 \mathrm{~cm}$ in size) [4] with multiple hyperechogenic, slightly defined, without certain margins, non-shadowing lesions, with the largest one measuring $5.3 \mathrm{~cm}$ in diameter, and also a gallbladder with multiple mobile hyperechogenic structures with distal acoustic shadowing and hepatomegaly with dilatation of the suprahepatic veins (Fig.1).

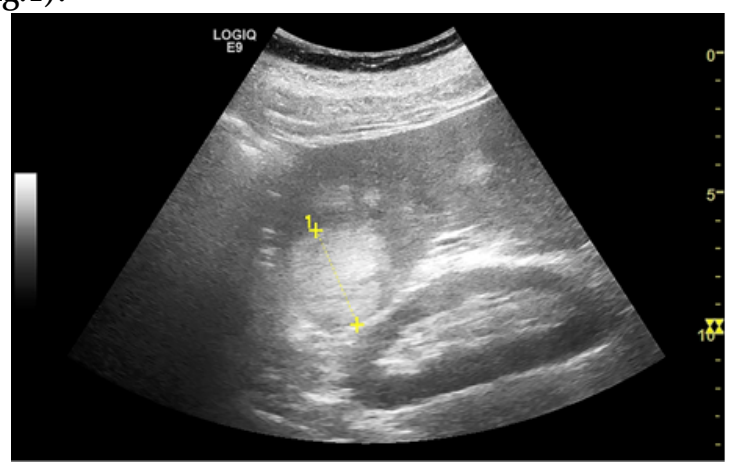

Fig. 1. Abdominal ultrasound imaging of the spleen

Further, a CEUS (on Logiq E9XD CLEAR GE Healthcare) SONOVUE-Bracco, Italy- $2.4 \mathrm{~mL}$ ) investigation was performed in order to establish the character of the lesion. During CEUS $[17,19]$ investigation we focused on the largest lesion previously identified on ultrasound, but two other lesions were also observed, especially during the late phase.

The lesion situated on the lower pole of the spleen was slightly hypoenhanced in the arterial time, with progressive washout and marked hypoenhancement in the late phase, at 3 minutes compared to the surrounding parenchyma. The remaining splenic lesions (previously described with the standard ultrasound) were isoenhanced in arterial phase, similar with the rest of the splenic parenchyma, with isoenhanced character in venous time and with late washout in parenchymatous time. A temporary conclusion

\footnotetext{
*email: roxanabuzas@yahoo.com; Phone: 0040722300488
} 


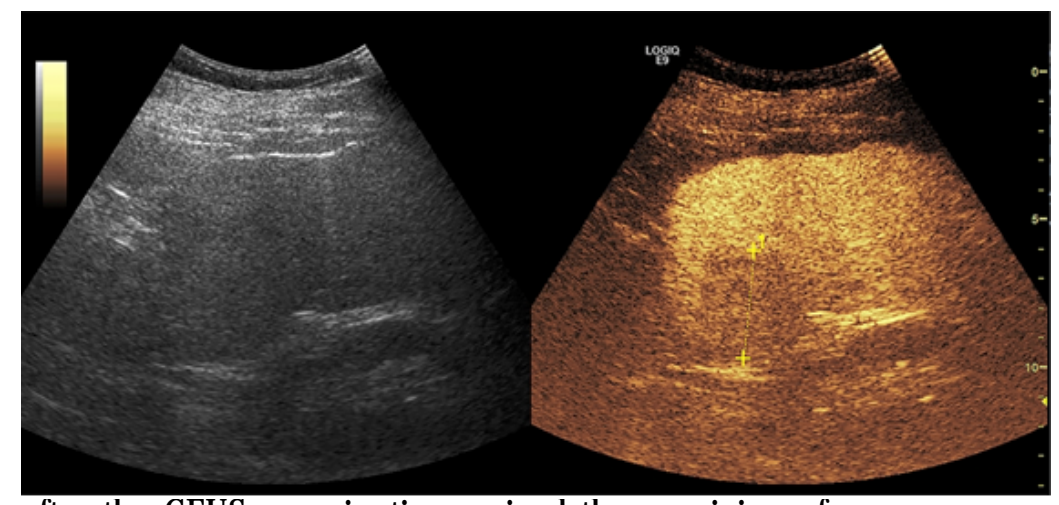

Fig. 2. Spleen lesions in CEUS

after the CEUS examinations raised the suspicion of a malignant splenic pathology (Fig.2).

Abdomen and pelvis contrast Nuclear Magnetic Resonance (MRI) was performed with the following pathological findings: spleen with the cranial-caudal diameter of $22.5 \mathrm{~cm}$, transverse diameter of $13 \mathrm{~cm}$, and a thickness of $6 \mathrm{~cm}$, non-homogeneous structure with multiple focal lesions, relatively well defined, but with irregular margins, some of the lesions deforming the splenic capsule, moderately hyperintense on the T2weighted image, discret hypointense on the T1-weighted image, in contrast with the normal splenic parenchyma; the maximal axial diameter of approximately $5.5 \mathrm{~cm}$ (the lesion situated in the inferior pole), hypointense in contrast with the normal splenic parenchyma. There were multiple abdominal lymphatic nodes identified, with a maximal axial diameter of approximately $9 \mathrm{~mm}$. The pelvic MRI was performed in order to exclude other neoplasic pathologies, identifying a non-homogenous structure with osteolisis aspect in iliac crest (Fig. 3).

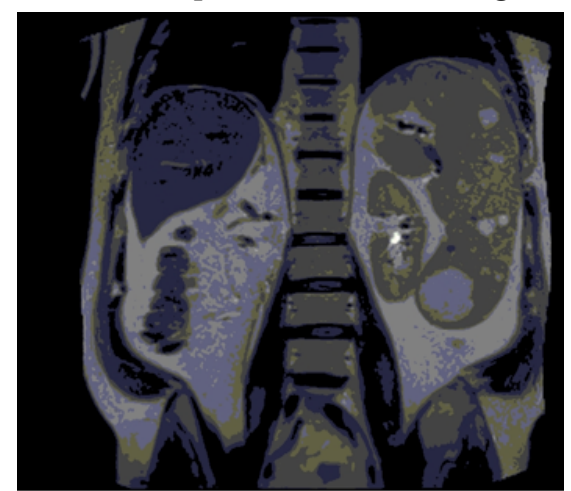

Fig. 3. Abdominal MRI aspect

Imagistic techniques findings were consistent with a high suspicion of splenic malignancy, a possible lymphoid infiltration [18]. Therefore, a decision was made to perform a peripheral blood smear, and a bone marrow aspiration biopsy. The peripheral blood smear revealed mild to severe lymphocytosis with villous lymphocytes, a variant form of hairy cell leukaemia; the nuclei have prominent nucleoli resembling to those of prolymphocytes, while the cytoplasm was weakly basophilic, with hair-like projections [1]. The unilateral iliac crest bone marrow biopsy confirmed the diagnosis.

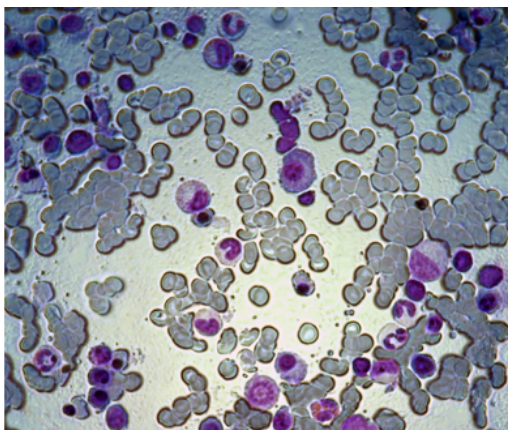

Fig. 4. Peripheral blood smear
We established the diagnosis of splenic lymphoma with bone metastases. The patient was referred for oncological treatment.

\section{Results and discussions}

Primary splenic lymphoma is very rarely reported $(<1 \%)$, being the most commonly encountered splenic malignancies. Hematological malignancy accounts for $15.6 \%$ of focal splenic lesions, arising in the white pulp and then spreading to the red pulp $[5,9,11]$. On B-mode ultrasound, lymphoma may mimic different type of lesions and, therefore, accurate characterization of focal splenic lesions is mandatory. Splenic involvement (either primary or secondary) lymphoma may be present as diffuse micro nodular infiltration, or multiple lesions of more than $1 \mathrm{~cm}$ in size, a mixture of these appearances, or a single solitary, hypoechoic mass $(60-70 \%)[2,3,5]$. Other possible findings include homogenous splenic enlargement or nonhomogenous aspect in the splenic parenchyma. As Ishida etal. stated in the report from 2001 [13], splenic lymphoma may show on B-mode ultrasound as a markedly hypoechoic to anechoic focal lesion, with acoustic enhancement. A slightly well-defined border of the lesion is a distinctive feature of a lymphoma, allowing differentiation from benign lesions. In our case, the biggest lesion observed, showed the characteristics of a benign lesion, although the only thing that pushed us for further investigation was the multiple site of the lesions correlated with the clinical and biological signs. Therefore, CEUS was performed as a tool for differentiation of a benign from a malign splenic lesion. The combination of contrast enhancement in the arterial phase with progressive hypoenhancement in the parenchymal phase, observed in our case, was typical for a malignant splenic lesion. As reported in Catalano's study, regularly disposed lesions (as the one in lymphoma) or anarchically disposed (metastasis) vessels can be seen first encircling and then entering the nodule and are especially recognizable during the early phase of pacification. Tumor tissue itself enhances less than the surrounding parenchyma $[6,7,11]$. The CEUS pattern of lymphoma has been described almost exclusively in a secondary splenic involvement. As stated in Caremani's study [5] - in the arterial phase these types of lesions showed isoenhancement in $37.5-46.3 \%$ of cases and a moderate hypoenhancement in $53 \%$ cases. In the parenchymal phase, there is a marked hypoenhancement in $100 \%$ of cases, due to a rapid wash-out. The malignant pathology (lymphomas or metastases) showed hypoenhancement in the arterial phase, in almost 50-57\% of cases, while $95 \%$ of cases showed wash-out in the late phase, according to Xiaoling's study [22]. In our study of primary splenic lymphoma, the CEUS pattern was the same as the one reported by Sutherland et al. [19] and was compatible with one of those described in the secondary splenic lymphoma of previous studies. Like Chiorean L et 
al. [8] described in their study in 2014, malignant lesions in the spleen show an enhancement in the arterial phase, followed by rapid wash-out, or progressively hypoenhancing aspect. This last aspect was described in some studies as having $100 \%$ sensitivity and $83 \%$ specificity for malignancies $[6,8,12,20]$.

Although in literature there is a description of CEUS' lymphoma enhancement, a typical pattern is not specific, overlapping that of metastases. Though we've had a clear enhancement pattern in our study, and a conclusion of malignancy could be established, there still remains a suspicion of metastases that showed an isoenhancement character in the arterial phase, but with a rapid wash-out in the late phase. Furthermore, hematological, histological investigations were needed. CEUS, MRI, all have limited specificity for both diffuse and focal splenic lymphomas. Moreover, the patient's medical history, together with imaging studies that identified bone metastases and no significant lymph nodes, sustaining a widespread neoplasm or a systemic lymphoma with splenic involvement, confirmed histopathologically.

\section{Conclusions}

CEUS was able to identify correctly a malignant lesion, promptly leading us to further hematological investigation, especially when interpreted in the clinical context of the case. Pathologic confirmation is necessary to make a definitive diagnosis.

The authors declare that the study was performed in accordance with the Declaration of Helsinky on ensuring research involving human subjects and that the patient has given his informed, written consent for the study.

\section{References}

1.BAIN, B.J ., CLARK, D.M., LAMPERT, I.A., WILKINS, B.S., Bone Marrow Pathology, erd Ed., John Wiley \& Sons, 2008.

2.BALLESTRI, S., LONARDO, A., ROMAGNOLI, D., LORIA, P., Journal of Medicine Ultrasonics 42(2), 2015, p. 251.

3.BHATIA, K., SAHDEV, A., REZNEK, R.H., Semin Ultrasound CT MR., 28, 2007, p. 12.

4.BLOCK, B., Abdominal Ultrasound: Step by Step. Thieme, 2011. 5.AREMANI, M., OCCHINI, U., CAREMANI, A., TACCONI, D., LAPINI, L., ACCORSI, A., MAZZARELLI, C., J ournal of Ultrasound 16(2), 2013, p. 65.
6.CATALANO, O., SANDOMENICO, F., VALLONE, P., D'ERRICO, A., SIANI, A., Seminars in Ultrasound CT and MRI, 27(5), 2006, p. 426.

7.CHIAVAROLI, R., GRIMA, P., TUNDO, P., J ournal of Clinical Ultrasound 39(6), 2011, p. 310.

8.CHIOREAN, L., ZDRENGHEA, M., BADEA, R., Med. Ultrason., 16(1), 2014, p. 48.

9.COMPERAT, E., BARDIER-DUPAS, A., CAMPARO, P., CAPRON, F., CHARLOTT, F., Arch Pathol Lab Med., 131, 2007, p. 965.

10.FERROZZI, F., BOVA, D., DRAGHI, F., GARLASCHI, G., Am. J. Roentgenol, 166, 1996, p. 1097.

11.GORG, C., FAORO, C., BERT, T., TEBBE, J., NEESSE, A., WILHELM, C., European J ournal of Radiology 80(2), 2011, p. 169.

12.HERBAY, V.A., BARREIROS, A.P., IGNEE, A., J Ultrasound Med., 28, 2009, p. 421.

13.ISHIDA, H., KONNO, K., ISHIDA, J., NAGANUMA, H., KOMATSUDA, T., SATO, M., WATANABE, S., Abdomen Imaging., 26, 2001, p. 529.

14.KRAUS. M.D., FLEMIND. M.D., VONDERHEIDE. R.H., Cancer 91, 2001, p. 2001.

15.LEEN, E., CECCOTTI, P., KALOGEROPOULOU, C., ANGERSON, W.J ., MOUG, S.J ., HORGAN, P.G., Am J Roentgenol. 186, 2006, p. 1511.

16.MARKRIN, V., AVITAL, S., WHITE, I., SAGI, B., SZOLD, A., Surg Endosc. 2008, (doi 10.1007/s00464-008-0024-8).

17.PISCAGLIA, F., NOLSOE, C., DIETRICH, C.F., COSGROVE, DO, GILJA, O.H., BACHMANN, NIELSEN, M., ALBRECHT, T., BAROZZI, L., BERTOLOTTO, M., CATALAN,O O., CLAUDON, M., CLEVERT, D.A., CORREAS, J.M., D'ONOFRIO, M., DRUDI, F.M., EYDING, J., GIOVANNINI, M., HOCKE, M., IGNEE, A., JUNG, E.M., KLAUSER, A.S., LASSAU, N., LEEN, E., MATHIS, G., SAFTOIU, A., SEIDEL, G.,, SIDHU, P.S., TER HAAR, G., TIMMERMAN, D., WESKOTT, H.P., Ultraschall Med., 33, 2012, p. 33.

18.SEMELKA, R. C., BROWN, M.A, ERSAN, A., Abdominal-Pelvic MRI. John Wiley \& Sons, 2016.

19.SUTHERLAND, T., TEMPLE, F., GALVIN, A., HENNESY, O., Insights into Imaging 2(5), 2011, p. 515.

20.TAFUTO S., CATALANO O., BARBARA G., SANDOMENICO, F., LOBIANCO, R., TORTORIELLO, A., FORMATO, R., COMELLA, P., SIANI, A., DI MEO, M., IAFFAIOLI, R. V., QUATTRIN, S., Frontier in Bioscience, Landmark, 11, 2006, p. 2224.

21.WILSON, S.R., JANG, H.J ., KIM, T.K., BURNS, P.N., J Ultrasound Med. 26, 2007, P. 775.

22.XIAOLING, YU, JIE, YU, PING, L., LIU, F., European Journal of Radiology 81, 2012, p. 430.

$\overline{\text { Manuscript received: } 11.02 .2019}$ 